\title{
The Neural Basis of Dominance Hierarchy Formation in Crayfish
}

\author{
DONALD H. EDWARDS, * FADI A. ISSA, AND JENS HERBERHOLZ \\ Department of Biology and Center for Behavioral Neuroscience, Georgia State University, Atlanta, Georgia 30302-4010
}

\begin{abstract}
KEY WORDS crayfish; dominance hierarchy formation; agonistic behavior patterns
\end{abstract}
\begin{abstract}
Fifty years of study of the nervous system and behavior of crayfish have revealed neural circuits for movements that are similar to those seen during formation of a dominance hierarchy. Given this background, it is of interest to ask what is understood about the neural substrates of dominance hierarchy formation. Here we will consider the social behavior that crayfish display in the wild and in the laboratory, and its relationship to movements released by activation of specific neural circuits. We will consider how these movements might be knit together to produce the behavior patterns that are characteristic of dominant and subordinate animals. Microsc. Res. Tech. 60:369-376, 2003. ๑ 2003 Wiley-Liss, Inc.
\end{abstract}

\section{BEHAVIOR IN THE WILD}

Crayfish live along the banks of streams or lakes, in underwater crevices or in burrows that they dig along the mud bank. Their burrow entrances are often clustered together, separated by less than a meter, so that upon leaving the burrows the animals gather in small groups on the adjacent stream bottom. In such circumstances, they necessarily compete for food and shelter resources, and for the opportunity to mate. The result of this competition is no highly organized society, but rather a set of dominance relationships that determine who will have first access to available resources and who will have the remains. We have little formal knowledge of social interactions among crayfish in the wild, except that dominance has its reward. Food repeatedly placed at one end of a zone populated by crayfish led to eviction of the smaller crayfish from burrows near the food by larger crayfish (Ranta and Linström, 1992). Informal personal observation of crayfish in the wild suggests that smaller ones usually give way to larger ones, and that fights are both rare and brief. We don't yet know how often any individual is likely to interact with another crayfish or with another specific individual. Nearly all of what is known results from observation of crayfish in laboratory aquaria where animals are usually matched in size and each animal has little opportunity to avoid others in the same aquarium. As a result, the level and duration of fighting is undoubtedly higher and longer than it would be in the wild, where there are usually many opportunities to escape and more objects and animals to draw attention (discussed in Goessmann et al., 2001; Peeke et al., 2000).

\section{BEHAVIORAL OBSERVATIONS IN THE LABORATORY}

Social interactions among crayfish were described by Huxley (1880), who noted that "Crayfishes, in fact, are guilty of cannibalism in its worst form; and a French observer pathetically remarks, that, under certain circumstances, the males "méconnaissent les plus saints devoirs;" and, not content with mutilating or killing their spouses, after the fashion of animals of higher moral pretensions, they descend to the lowest depths of utilitarian turpitude, and finish by eating them." Cannibalism occurs most frequently when crayfish are crowded, which is the condition that is also most favorable for observing the formation of dominance hierarchies. Bovbjerg (1953) and Lowe (1956) were the first to note that like many other animals, crayfish in small groups (six or less) formed linear dominance hierarchies that were transitive, such that if animal A was dominant to $\mathrm{B}$ and $\mathrm{B}$ was dominant to $\mathrm{C}$, then $\mathrm{A}$ was dominant to C. Size is the major factor in determining dominance order (Pavey and Fielder, 1996), although both individual aggressiveness (Issa et al., 1999) and experience can be important factors as well (Lowe, 1956).

During pairwise interactions, dominance is also determined primarily by the relative sizes of the two animals, although other factors, including residence status and reproductive state can become significant (Figler et al., 1995, 1999). When they differ significantly in size, the smaller avoids the approach of the larger by retreating or tailflipping. More evenly matched animals pass through a gradually escalating series of interactions, beginning with a mutual size comparison. The two animals simultaneously extend their claws to the farthest extent laterally, upward and forward, towards their opponent, to form a mirrored image as the opposing claw tips touch (Bruski and Dunham, 1987; Huber and Kravitz, 1995). This "meral spread" is identical to the "defense posture" that is evoked by visual looming stimuli (Atwood and Wiersma, 1967; Kelly and Chapple, 1990). If this size comparison fails to resolve the dominance relationship, the two animals perform a dance very similar to that

*Correspondence to: Donald H. Edwards, Department of Biology and Center for Behavioral Neuroscience, Georgia State University, Atlanta, GA 30302-4010 E-mail: biodhe@langate.gsu.edu

Received 14 June 2001; accepted in revised form 6 December 2001 DOI 10.1002/jemt.10275

Published online in Wiley InterScience (www.interscience.wiley.com). 


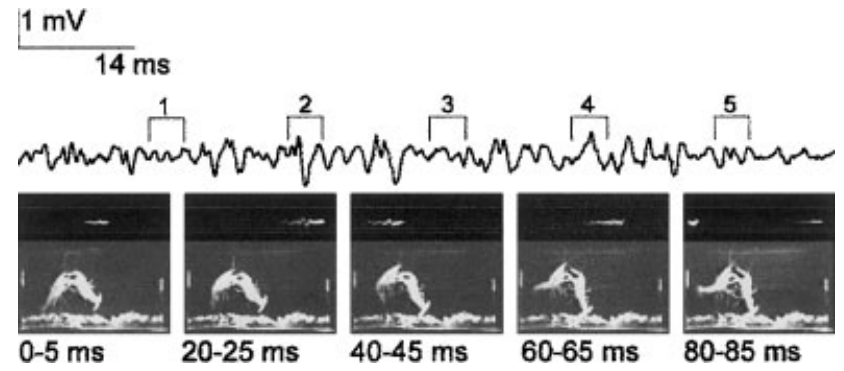

Fig. 1. Offensive tailflipping during a dominance contest. Five video frames, each 5 -ms duration, at the times indicated after the first display one cycle of an offensive tailflip by the crayfish on the left. Electric field potential recording from a pair of electrodes in the water at either end of the aquarium (left and right sides of each frame) is displayed above the video frames; the period of each frame is indicated above. An oscilloscope display of the same potential is shown in the top portion of each frame; this was used to identify the portion of the potential coincident with the frame. Reproduced from Herberholz et al. (2001) with permission of the publisher.

seen in lobsters (Huber and Kravitz, 1995), in which one animal advances and the other retreats, followed by a reversal of direction (Goessmann et al., 2001). As each animal moves forward, it lashes the other with its antennae while ejecting urine from the antennal glands directly toward the opponent (Breithaupt and Eger, 2001; Bushmann and Atema, 1994). This stage is followed by one in which the animals grasp each other with their claws and wrestle, each trying to turn the other over and move it about. Again, the contest could easily end at this point, with the rapid escape of one animal from the other. Finally, all-out fighting occurs, in which the animals strike at each other with the major claws, grapple each other, and perform offensive tailflips. These last behavior patterns are rapid tail flexions that thrust the tailflipping animal up into the water column above its opponent, which is dragged upward (Fig. 1; Herberholz et al., 2001). Unlike aggressive tailflips performed by fighting lobsters (Mello et al., 1999), offensive tailflips do not produce dismemberment of the opponent, perhaps because the thrust they produce is submaximal, and well below the thrust produced during a tailflip escape. Nonetheless, offensive tailflips appear to demonstrate the power of the tailflipping animal to the animal being dragged. Finally, at some point during the contest and often at the end of a bout of offensive tailflipping by the opponent, one animal will initiate a series of repeated tailflip escapes and retreats that breaks off the fight and signals its defeat. The initial dominance decision is made: the retreating animal is the subordinate and the attacking animal is dominant. Thereafter, the patterns of behavior expressed by the two animals are quite different (Herberholz et al., 2001).

An example of the sequence of behaviors produced by a pair of juvenile crayfish during the first 30 minutes of dominance hierarchy formation is seen in Figure 2. The two animals' behavior was scored for occurrence of three offensive behavior patterns, attack, approach, and offensive tailflip, and five defensive behaviors, retreat, lateral giant (LG) escape tailflip, medial giant (MG) escape tailflip, non-giant (NG) escape tailflip, and swimming. (LG, MG, and NG tailflips derive their

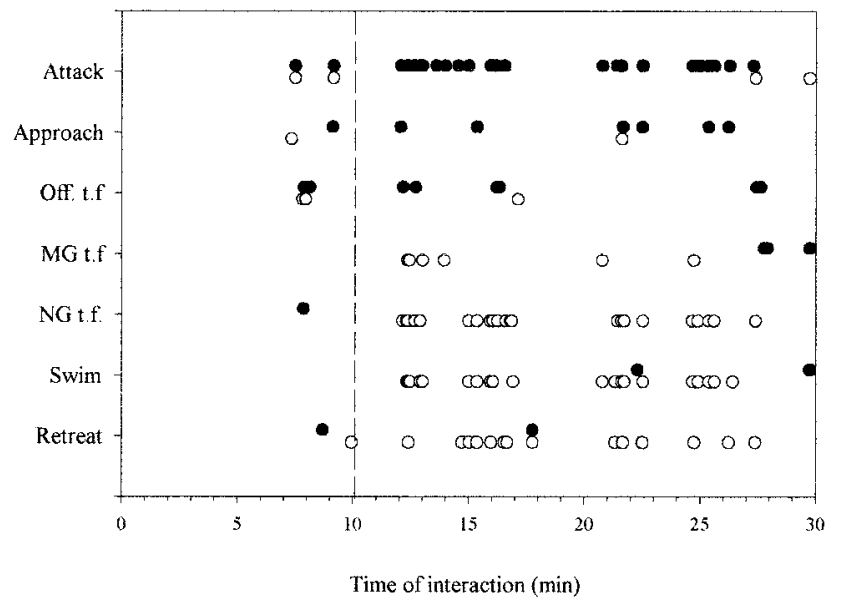

Fig. 2. Ethogram of dominance hierarchy formation between two juvenile crayfish. Occurrences of each of 7 behaviors during 30 minutes following pairing of two unfamiliar juvenile crayfish. Dashed line marks time of dominance decision: thereafter one animal (open circles) displays defensive behavior in response to the other's aggressive behavior. Off. t.f.: offensive tailflip; MG t.f.: Medial Giant tailflip, NG t.f.: Non-giant tailflip. Reproduced from Herberholz et al. (2001) with permission of the publisher.

names from discrete central command systems that produce them, and are discussed in more detail below.) For this pair, agonistic interactions began 7 minutes after the animals were introduced, and were balanced between the two animals: both initiated attacks, approaches, and offensive tailflips. Defensive behavior was minimal during this period: one animal tailflipped away from one encounter and retreated from a second, while the other animal only retreated once. A pause in their interactions lasted nearly 2 minutes (Fig. 2, dashed vertical line), after which one animal (Fig. 2, filled symbols) initiated a vigorous series of attacks, approaches and bouts of offensive tailflips, while the other (Fig. 2, open symbols) responded with purely defensive measures, including MG and non-giant escape tailflips, swims away from the attacker, and retreats. The first animal's attacks persisted throughout the remainder of the half hour, broken by pauses and the occasional aggressive response of the defending animal, which otherwise responded with escape tailflips, swims, and retreats from the aggressor. LG tailflips failed to occur during this interaction, and occurred only once in encounters observed between eight pairs of animals, when a dominant struck the abdomen of a subordinate with a claw (Herberholz et al., 2001). A rise in the stimulus threshold of the LG tailflip that occurs during fighting may account for the absence of LG tailflips (Krasne et al., 1997).

Once the initial dominance relationship is established, the frequency of agonistic encounters declines steadily (Goessmann et al., 2001; Issa et al., 1999). This is seen in observations of small groups of socially naïve juvenile crayfish that were introduced simultaneously and kept together for 2 weeks (Fig. 3; Issa et al., 1999). The decline in agonistic encounters was accompanied by a corresponding reduction in the frequency of attacks and escapes, and a rise in the frequency of retreats. As the group became more peaceful, subordi- 


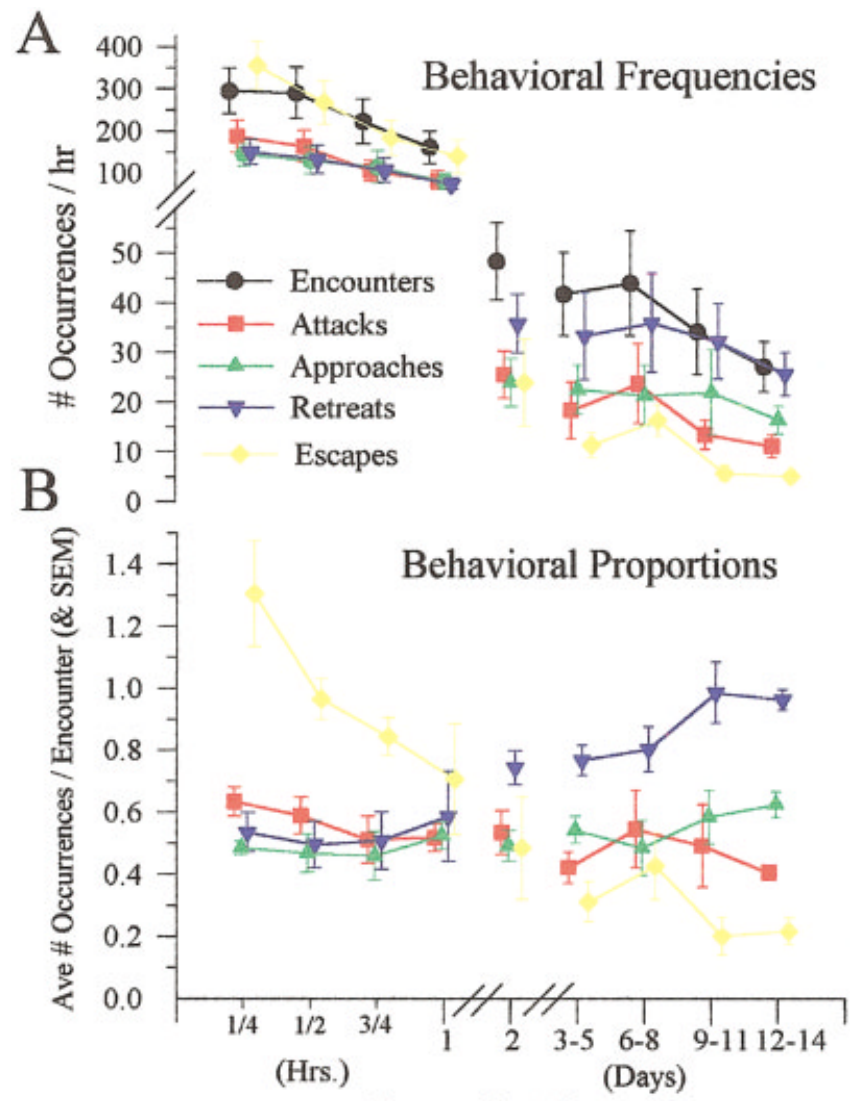

Observation Time

Fig. 3. Decline in the frequency of aggressive interactions following during formation of a dominance hierarchy in each of five groups of five juvenile crayfish. Top: Average frequencies (and SD) of encounters between any two animals and of each of four behaviors: attacks, approaches, retreats, and escapes. Measurements were made over 15-minute periods during the first hour of group formation and over 1-hour periods during the following days. Bottom: Relative proportions of each behavior. Reproduced from Issa et al. (1999) with permission of the publisher.

nate animals replaced the use of tailflip escapes with ambulatory retreats, in which the animals backed off at the approach of the superdominant animal. Contact was avoided and the interval between fights increased. Similar results were recently obtained from groups of four adult crayfish (Astacus astacus) in which the animals were separated except during 2-hour observation periods on each of 5 days (Goessmann et al., 2001).

\section{NEURAL CIRCUITS FOR RELEVANT BEHAVIOR PATTERNS}

The individual behaviors used in agonistic interactions, including escape, postural changes, forward walking, backward walking, and defense, have been shown to result from activation of discrete neural circuits that can be excited by specific sensory stimuli or by command systems of central neurons. However, with the exception of escape and defense, little is known about how these circuits are excited in a social context to produce adaptive patterns of behavior (Herberholz et al., 2001).

\section{Escape Tailflips}

Three different neural circuits mediate tailflip escape responses. Two of these have giant interneurons as command elements. The lateral giant (LG) interneurons respond to a phasic tactile stimulus on the abdomen with a single spike that activates pre-motor interneurons and motor neurons in a highly stereotyped manner to produce an equally stereotyped tailflip escape response (Edwards et al., 1999; Wine and Krasne, 1982). The tailflip results from a strong, rapid flexion of the anterior abdominal joints and simultaneous promotion of the uropods. This causes the animal to "jackknife" upward and forward, away from the attack. The pair of medial giant (MG) interneurons respond to similar strong, phasic tactile stimuli to the front of the animal, or to rapidly looming visual stimuli. A single spike in the MGs moves caudally along both sides of the nerve cord and excites the same pre-motor interneurons and motor neurons in a different segmental pattern to produce a pattern of rapid flexion at each abdominal joint. This pattern thrusts the animal backward away from the frontal attack. The non-giant circuit is much less understood, but is known to consist of a set of non-giant interneurons that excite sets of abdominal fast flexor motor neurons in a pattern that will carry the animal away from the point of attack. Nongiant tailflips are evoked by more gradually developing noxious stimuli such as pinching a limb, but can also be produced "voluntarily," in which the animal tailflips in response to no obvious stimulus, and "swimming," a repetitive series of flexions and extensions that propels the animal backward rapidly through the water. Whereas the latencies of the giant-mediated tailflips are $10-25 \mathrm{~ms}$, depending on the size of the animal, the latency of the non-giant tailflip is four to eight times greater. This longer latency may be attributed to the time required to determine both the direction of the source of the attack and the motor pattern required to move the animal in the opposite direction.

\section{Posture}

Body posture depends on the behavioral context. Crayfish may rest on their ventral surface, with the abdomen flexed or extended, or hold themselves more erect, often while walking. Abdominal postural motor neurons, which are always tonically active in dissected preparations, are silent in freely behaving resting animals, suggesting that the overall level of nervous excitability then is low (Edwards, 1984). When the animal is aroused, the body posture can be elevated or supine, depending on the context: the posture of dominant animals, and animals engaged in a dominance contest tends to be elevated, whereas that of subordinate animals is more supine (Livingstone et al., 1980). The control of body posture is produced by a balance between central commands and local reflex systems (Cattaert and Le Ray, 2001; Fields, 1966). Abdominal posture is controlled by a command network of interneurons, subsets of which are activated to produce specific flexed or extended postures (Jones and Page, 1986; Kennedy et al., 1966; Miall and Larimer, 1982a,b). Overall control of body posture may be held by interneurons in the circumeoesophageal connectives that activate different body postures, usually in the 
context of a specific behavior such as walking or defense (Bowerman and Larimer, 1974). Local control systems include a set of proprioceptors in the limbs, abdominal segments, and ventral nerve cord that mediate both resistance and assistance reflexes, and a set of photoreceptors in each abdominal ganglion that excites postural flexion motor neurons locally and in all of the more caudal abdominal ganglia (Clarac et al., 2000; Edwards, 1984).

\section{Walking}

Walking provides the primary means of locomotion within small areas along a stream- or lake bed, or during overland treks between watersheds. During social interactions, approaches are mediated by forward walking, whereas retreats are mediated by backward walking, although forward and backward walking can be components of other behaviors as well. Forward walking is usually accompanied by abdominal extension, whereas backward walking is often accompanied by a cyclical pattern of abdominal flexion and extension. Networks of interneurons that promote cyclical patterns of abdominal flexion and extension (Moore and Larimer, 1988, 1993) are tied into the network that produces backward walking in response to central commands, visual looming stimuli, or illumination of the caudal photoreceptor (Kovac, 1974; Miall and Larimer, 1982b; Simon and Edwards, 1990). This network consists of two levels of interneurons, the pattern interneurons (PIs) and the partial pattern interneurons (PPIs; Moore and Larimer, 1993). The PIs are a set of electrically coupled interneurons, each of which extends one or two segments along the ventral nerve cord and can excite the entire motor program. The PPIs conduct the PI signal to the segmental motor neurons. Other sets of interneurons produce forward walking. Motor patterns for either backwards or forwards walking can be excited by application of muscarinic cholinergic agonists (Chrachri and Clarac, 1990; Cattaert et al., 1995); these rhythms can be entrained by stimulation of proprioceptive afferents (Elson et al., 1992; Leibrock et al., 1996). Circuitry mediating both resistance and assistance reflexes has been described and shown to be active in enabling normal walking (Clarac et al., 2000).

\section{Meral Spread}

Meral spread is used both offensively and defensively to confront an opponent with the crayfish's principal weapons, the large claws. Meral spread is used offensively as one of several behaviors that include grappling and striking the opponent. Meral spread is also part of a defense response that is triggered by visual looming stimuli and consists of an elevation and spread of the claws, a widened stance, an extended abdomen, and a flattened tail. It is a low-threshold response, as anyone who has approached an aquarium containing crayfish has observed. The defense response is guided by visual stimuli, as the direction of the body axis and thrust of the claws will follow the movement of a visually threatening stimulus (Kelly and Chapple, 1990). The defense response can also be evoked by stimulation of any one of a set of three to six defense interneurons (DIs) in the circumesophageal connectives (Atwood and Wiersma, 1967; Bowerman and Larimer, 1974). Both the DIs and the defense response are subject to facilitation and habituation, and to modulation by the "excited state" of the animal. The DIs appear to be monosynaptically excited by "jittery movement detector" (JMD) interneurons found in the optic nerve (Glantz, 1974). Consequently, the defense response appears to be evoked by an ensemble of DIs that are excited by a small group of JMDs as they respond to a looming stimulus. Although it is likely that many of the same elements also mediate offensive use of meral spread displays, the circuitry has not yet been studied in this context.

\section{USE OF NEURAL CIRCUITS IN DOMINANCE HIERARCHY FORMATION}

Many of the different patterns of behavior displayed during hierarchy formation can be related directly to those for which neural circuits have been described. Attack and approach behaviors make use of forward walking, whereas retreat relies on backward walking; the neural substrates for these agonistic behaviors are likely to include activation of the appropriate walking command circuits. The defense posture that occurs in response to the approach or attack of another crayfish is likely to result from excitation of the DIs and other postural command elements by the JMDs as they respond to looming stimuli provided by the approach of the other crayfish. The meral spread that accompanies forward walking during an attack may be mediated by some of the DIs that produce the defense response. Defensive behavior can include the three forms of tailflip escape that are released by their respective neuronal command systems, whereas offensive tailflipping is likely to be released by yet another command system.

Activation of the different neural circuits and patterns of behavior are highly coordinated, but the pattern of coordination can change dramatically, as when an animal breaks off the contest and escapes. In the example shown in Figure 2, offensive behaviors were frequent and defensive behaviors were rare before that point, whereas afterward the reverse was true of the new subordinate. Before the status decision, MG and non-giant escapes of the prospective subordinate were rare and occurred in response to an approach or attack by the prospective dominant as the two animals faced each other. After the decision, many of the MG and non-giant escape tailflips displayed by the new subordinate resulted from no actual contact with the aggressor; they appeared to be "voluntary" or in response to the slow approach of that animal. This suggests that the excitability of these defensive circuits suddenly changed from being low before the subordinate's decision to retreat to very high afterwards, while the excitability of circuits that mediate offensive action (approaches, attacks, offensive tailflips) changed in the opposite direction. In the dominant animal, the excitability of circuits that evoke defensive behavior remained low throughout, whereas that for offensive behavior remained high.

The failure of LG to respond more than once is consistent with these changes. The animals faced each other throughout these bouts, and so provided little opportunity for an attack on the tail that would excite LG. At the same time, LG also failed to respond to the inadvertent bump of a retreating animal into a side of 
the aquarium, suggesting that LG's excitability is kept low throughout these encounters. This suggestion is supported by results from experiments on established dominant and subordinate adult animals (Krasne et al., 1997), in which LG's stimulus threshold was shown to rise substantially in subordinates and less in dominants during fighting, but not before or after.

\section{MECHANISMS OF CIRCUIT ACTIVATION AND INHIBITION}

The sudden and persistent shift in the excitability of suites of neural circuits has been seen before in crayfish, and occurs when a feeding animal is suddenly challenged by a threatening stimulus (Bellman and Krasne, 1983). If the food was readily portable, the animal tailflipped quickly away. The normally low excitability of LG increased during feeding, and the circuit and escape behavior were triggered by relatively weak stimuli directed at the abdomen. If the food was heavy or hard to move, the LG excitability was low, and even strong hits to the abdomen would not evoke escape. These variations in LG's excitability were attributed to the effects of "tonic inhibition" of LG (Vu et al., 1993; Vu and Krasne, 1993), which is active during the display of behaviors that are mutually exclusive with escape, including restraint, walking, defense, and feeding (Beall et al., 1990). Activation of LG or MG also inhibits abdominal postural movements (Kuwada and Wine, 1979; Kuwada et al., 1980). This mutual inhibition provides the animal with control over the release of different discrete patterns of behavior, and does not have to be centrally generated by a master decision network. Mutual inhibition among circuits that produce different behavior patterns provides a mechanism for behavioral choice in which the "decision" to display any particular behavior is distributed across the circuits (Edwards, 1991). It may be, then, that the decision to break off aggressive behavior and initiate defensive behavior by the new subordinate reflects such a shift between excitation and inhibition among the circuits that organize different behavior patterns.

\section{SEROTONERGIC NEUROMODULATION AND THE FORMATION OF DOMINANCE HIERARCHIES}

Although tonic inhibition might account for the immediate shift in the excitability of the affected circuits, it is likely that longer-lasting mechanisms activated by neuromodulators are involved as well. Neuromodulators that have been identified as affecting the social behavior of decapod crustaceans include the monoamines serotonin and octopamine (Kravitz, 2000), steroid hormones (Bolingbroke and Kass-Simon, 2001), and peptide stress hormones (Chang et al., 1999b; Kravitz et al., 2001). Serotonin is the best understood of these substances in crayfish, although others, including these and as yet unidentified substances, may play important roles. When injected into crayfish, lobsters, squat lobsters, and prawns, serotonin and octopamine released postures that resembled those of dominant and subordinate animals, respectively (Antonsen and Paul, 1997; Livingstone et al., 1980; Sosa and Baro, 2001). Although serotonin injections did not produce behavior patterns that were specifically associated with aggression (Tierney and Mangiamele, 2001), manipulations that altered serotonin levels delayed a subordinate's decision to retreat from an aggressive dominant (Doernberg et al., 2001; Huber et al., 1997, 2001; Huber and Delago, 1998). The effect of increased serotonin on withdrawal was blocked by fluoxetine, which inhibits uptake of serotonin. This result suggests that the delay in withdrawal results from extra serotonin that is taken up and released by serotonergic neurons onto normal targets.

We don't know what those targets are, but we do know that serotonin modulates the excitability of abdominal postural circuits (Djokaj et al., 2001; HarrisWarrick and Kravitz, 1984, 1985), claw opening (Qian and Delaney, 1997), escape circuits (Glanzman and Krasne, 1983), heart rate (Florey and Rathmayer, 1978), locomotion (Gill and Skorupski, 1996; Glusman and Kravitz, 1982; Pearlstein et al., 1998; Rossi-Durand, 1993), swimmeret beating (Barthe et al., 1993), digestion (Ayali and Harris-Warrick, 1999; Katz and Harris-Warrick, 1990; Tierney et al., 1999), and gut movements (Musolf and Edwards, 2000). In most of these systems, serotonin acts to increase or decrease the system's "gain" (Kravitz, 1988, 2000; Ma et al., 1992), to enhance the excitation or inhibition produced by the local transmitter.

The type of serotonergic modulatory gain-setting that occurs, whether facilitation or inhibition, and whether brief or long-lasting, depends on the receptors and second-messenger systems, and also on the pattern of exposure (Teshiba et al., 2001). For example, the LG's response was facilitated by rapid application of low concentrations $(1 \mu \mathrm{M})$ of serotonin, but was inhibited by rapid application of higher concentrations $(50 \mu \mathrm{M})$. The same high concentration had a facilitative effect when applied slowly (i.e., it reached 95\% of final concentration after 25 minutes), presumably because activation of a facilitatory mechanism early in the application prevented activation of an inhibitory mechanism when the concentration reached levels that could activate it. Brief exposures (e.g., 10 minutes) were immediately followed by a return of the system to basal responsiveness, whereas longer exposures ( $>30$ minutes) evoked long-term (i.e., at least 5 hours) facilitation when the serotonin was removed, regardless of whether the initial effect was facilitatory or inhibitory.

Different patterns of exposure can result from different methods of serotonin release, whether synaptic, paracrine, or endocrine. All of these patterns appear to occur in the crayfish, which has a large complement of serotonergic neurons and an open circulatory system (Beltz and Kravitz, 1983; Real and Czternasty, 1990). Patterns of release can be matched with patterns of uptake to create an individual pattern of exposure; the pattern of exposure may then be matched to receptors and second-messenger systems that respond preferentially to that pattern (Teshiba et al., 2001).

One might imagine, then, that different behavioral states would be associated with different patterns of modulator release and modulatory effect (Blitz et al., 1999; Kravitz, 2000). Preliminary evidence that this occurs in crayfish of different social status has been obtained from recordings of the pairs of large serotonergic neurons in the last thoracic (T5) and first abdominal (A1) ganglia. These tonically active cells modulate the abdominal postural and thoracic locomotor 
systems in both crayfish and lobsters. They project unilaterally in their own and more rostral ganglia, and they are neurosecretory, with endings on adjacent ganglionic third nerves (Beltz and Kravitz, 1987; HarrisWarrick and Kravitz, 1984; Ma et al., 1992; Real and Czternasty, 1990). A light touch to one side of the A1 segment of restrained, decapitated dominant crayfish excited ipsilateral serotonergic neurons and inhibited their contralateral homologs; the same touch of subordinates produced either bilateral excitation or bilateral inhibition of the A1 and T5 serotonin neurons (Drummond and Edwards, 1998). When delivered to unexpecting, freely behaving animals, the same touch always caused a dominant animal to make a rapid turn towards the stimulus source to confront it, whereas subordinate animals consistently moved straight forward or straight backward away from the stimulus source (Song et al., 2000). If the pattern of serotonin release depends on the firing frequency, then the asymmetrical responses of modulatory neurons in dominants increased the amounts of serotonin released ipsilateral to the touch and reduced the amounts released contralaterally. This asymmetric release may help account for the asymmetry of the turning response of dominant animals. In a similar vein, the bilateral increases or decreases in neuronal firing seen in subordinates should produce bilateral increases or decreases in released serotonin. These symmetric changes in release may help account for the symmetrical forward or rearward retreats evoked by the same touch stimulus in these animals.

\section{LONG-TERM ADAPTATIONS TO A CHANGE IN SOCIAL STATUS}

Longer-term changes in social behavior may require corresponding longer-term changes in the neuromodulatory systems and circuits that mediate the different components of social behavior. For example, the 2-week decline in agonistic activity among five juvenile crayfish that occurred following the initial formation of a dominance hierarchy was accompanied by a decline in the frequency of tailflip escape behavior of social subordinates and a rise in the frequency of retreats (Fig. 3; Issa et al., 1999). A similar decline in the aggressiveness of paired animals was accompanied by a change in the modulatory effect of serotonin on the LG neuron (Yeh et al., 1996, 1997). Serotonin changed from being facilitatory in newly paired subordinates to being inhibitory after 2 weeks of pairing, whereas serotonin remained facilitatory in their dominant partners throughout. These changes, which appear to have resulted from changes in the population of serotonin receptors, were readily reversible over the same timecourse by re-isolation of the subordinate or by enabling the subordinate to become dominant to another animal. We don't know how these changes might apply to a mid-ranking animal, nor do we know whether dominance relationships in the wild persist long enough for these changes to develop, although it seems likely. Crayfish cluster in small groups along the banks of streams or ponds where they interact both competitively and cooperatively. It is likely that these groups persist in a stable configuration for the 2 weeks needed to produce changes in receptor populations.
It is likely that other circuits experience similar longterm changes in neuromodulation. The MG and nongiant circuits, which were very active in new subordinates (Herberholz et al., 2001), were rarely excited after animals had been grouped for 2 weeks (Issa et al., 1999). They appear to have experienced long-term changes in neuromodulatory effect similar to those produced by serotonin in LG. The backward walking circuits that mediate retreat might become more excitable as the crayfish learns to avoid the approach of the dominant animal, whereas the defense circuits may become less excitable.

Such gradual changes require a daily signal that reports to the rest of the nervous system, including the abdominal ganglia where the LG is located, about the current social status of the animal. That signal appears to be humoral and may be the release of serotonin itself. The same changes in the modulatory effect of serotonin on LG in new subordinate and dominant animals have been achieved in animals where the ventral nerve cord was cut between the abdomen and thorax before the animals were paired to form the hierarchy (Arfai and Krasne, 1999). If the changes in the modulatory effect of serotonin result from a change in the population of serotonin receptors (Yeh et al., 1997), then these results indicate that a humoral factor released from the anterior nervous system is sufficient to induce changes in the sensitivity of LG to serotonin by changing the population of serotonin receptors in the cell. Given that patterns of serotonin release differ in dominant and subordinate animals (Drummond and Edwards, 1998), it may be that the pattern or level of serotonin release tells the LG and other neurons which serotonin receptors to display.

\section{CONCLUSIONS}

This sketch of our knowledge of the neural circuits, neuromodulation, and social behavior of crayfish shows that the neural mechanisms that underlie social behavior are accessible to reductionist explanation. Nonetheless, many holes remain in the story. All of the agonistic behavior patterns described here are much more complex and variable than the simple movements evoked by stimulation of individual command circuits. How these and other circuits are orchestrated to produce these complex behaviors remains unclear. We are also ignorant of the substrate of the subordinate's decision to escape from the dominant. That decision determines social dominance status and affects the behavioral state profoundly, and we have no idea where it is mediated in the brain or how it is communicated to the rest of the nervous system. Serotonin has received the most attention in this article, but undoubtedly other transmitters and hormones play key roles. Octopamine was identified early with serotonin as affecting cells (e.g., LG) and systems (e.g., escape, posture) that are important to social behavior (Glanzman and Krasne, 1983; Livingstone et al., 1980); but the detailed experiments on this and other substances (e.g., dopamine, and peptides such as crustacean hyperglycemic hormone) are just beginning (Chang et al., 1999a). Hormones such as 20-hydroxyecdysone have been shown to affect peripheral synapses in crayfish (Cooper and Ruffner, 1998) and aggressive behavior in lobster (Bolingbroke and Kass-Simon, 2001), but effects on 
CNS circuits and functions remain to be described. The receptors for serotonin and other transmitters have yet to be identified, characterized, and localized; this will tell us how the neuromodulatory and neurohormonal systems adapt to changes in an animal's social status. Finally (but by no means exclusively), the feedback loops that link social experience to changes in neuromodulation to changes in circuit activation to changes in social behavior to changes in social experience are seen only in outline; most of the important details are missing. Nonetheless, a framework for how the nervous system governs social behavior and how social experience affects nervous function has emerged and the prospect for building upon it is exciting.

\section{REFERENCES}

Antonsen BL, Paul DH. 1997. Serotonin and octopamine elicit stereotypical behaviors in the squat lobster Munida quadrispina (Anomura, Galatheidae). J Comp Physiol A 181:501-510.

Arfai N, Krasne FB. 1999. Social experience-dependent changes in response of crayfish Lateral Giant neurons to 5-HT may be induced by humoral factors. Soc Neurosci Abstr 25:168.

Atwood HL, Wiersma CAG. 1967. Command interneurons in the crayfish central nervous system. J Exp Biol 46:249-261.

Ayali A, Harris-Warrick RM. 1999. Monoamine control of the pacemaker kernel and cycle frequency in the lobster pyloric network. J Neurosci 19:6712-6722.

Barthe JY, Bevengut M, Clarac F. 1993. In vitro, proctolin and serotonin induced modulations of the abdominal motor system activities in crayfish. Brain Res 623:101-109.

Beall SP, Langley DJ, Edwards DH. 1990. Inhibition of escape tailflip in crayfish during backward walking and the defense posture. J Exp Biol 152:577-582.

Bellman KL, Krasne FB. 1983. Adaptive complexity of interactions between feeding and escape in crayfish. Science 221:779-781.

Beltz BS, Kravitz EA. 1983. Mapping of serotonin-like immunoreactivity in the lobster nervous system. J Neurosci 3:585-602.

Beltz BS, Kravitz EA. 1987. Physiological identification, morphological analysis, and development of identified serotonin-proctolin containing neurons in the lobster ventral nerve cord. J Neurosci 7:533546.

Blitz DM, Christie AE, Coleman MJ, Norris BJ, Marder E, Nusbaum MP. 1999. Different proctolin neurons elicit distinct motor patterns from a multifunctional neuronal network. J Neurosci 19:54495463.

Bolingbroke M, Kass-Simon G. 2001. 20-hydroxyecdysone causes increased aggressiveness in female American lobsters, Homarus americanus. Horm Behav 39:144-156.

Bovbjerg RV. 1953. Dominance order in the crayfish Oconectes virilis (Hagen). Physiol Zool 26:173-178.

Bowerman RF, Larimer JL. 1974. Command fibres in the circumoesophageal connectives of crayfish. J Exp Biol 60:95-117.

Breithaupt T, Eger P. 2002. Urine makes the difference: Chemical communication in fighting crayfish made visible. J Exp Biol 205 : 1221-1231.

Bruski CA, Dunham DW. 1987. The importance of vision in agonistic communication of the crayfish Orconectes rusticus. I: An analysis of bout dynamics. Behavior 103:83-107.

Bushmann P, Atema J. 1994. Aggression-reducing courtship signals in the lobster, Homarus americanus. Biol Bull 187:275-276.

Cattaert D, Le Ray D. 2001. Adaptive motor control in crayfish. Prog Neurobiol 63:199-240.

Cattaert D, Pearlstein E, Clarac F. 1995. Cholinergic control of the walking network in the crayfish Procambarus clarkii. J Physiol Paris 89:209-220.

Chang ES, Chang SA, Beltz BS, Kravitz EA. 1999a. Crustacean hyperglycemic hormone in the lobster nervous system: localization and release from cells in the subesophageal ganglion and thoracic second roots. J Comp Neurol 414:50-56.

Chang ES, Chang SA, Keller R, Reddy P, Sr., Snyder MJ, Spees JL. 1999b. Quantification of stress in lobsters: Crustacean hyperglycemic hormone, stress proteins, and gene expression. Am Zool 39:487495.

Chrachri A, Clarac F. 1990. Fictive locomotion in the fourth thoracic ganglion of the crayfish, Procambarus clarkii. J Neurosci 10:707719 .
Clarac F, Cattaert D, Le Ray D. 2000. Central control components of a "simple" stretch reflex. Trends Neurosci 23:199-208.

Cooper RL, Ruffner ME. 1998. Depression of synaptic efficacy at intermolt in crayfish neuromuscular junctions by 20 -hydroxyecdysone, a molting hormone. J Neurophysiol 79:1931-1941.

Djokaj S, Cooper RL, Rathmayer W. 2001. Presynaptic effects of octopamine, serotonin, and cocktails of the two modulators on neuromuscular transmission in crustaceans. J Comp Physiol A 187: 145-154.

Doernberg SB, Cromarty SI, Heinrich R, Beltz BS, Kravitz EA. 2001. Agonistic behavior in naïve juvenile lobsters depleted of serotonin by 5,7-dihydroxytryptamine. J Comp Physiol A 187:91-103.

Drummond J, Edwards DH. 1998. Effect of social experience on reflex responses of serotonergic neurons in crayfish. Fifth Intl Cong Neuroethol Abstr 208.

Edwards, DH. 1984. Crayfish extraretinal photoreception. I. behavioural and motoneuronal responses to abdominal illumination. $J$ Exp Biol 109:291-306.

Edwards DH. 1991. Mutual inhibition among neural command systems as a possible mechanism for behavioral choice in crayfish. J Neurosci 11:1210-1223.

Edwards DH, Heitler WJ, Krasne FB. 1999. 50 years of a command neuron: The neurobiology of escape behavior in the crayfish. Trends Neurosci 22:153-161.

Elson RC, Sillar KT, Bush BM. 1992. Identified proprioceptive afferents and motor rhythm entrainment in the crayfish walking system. J Neurophysiol 67:530-546.

Fields HL. 1966. Proprioceptive control of posture in the crayfish abdomen. J Exp Biol 44:455-468.

Figler MH, Twum M, Finkelstein JE, Peeke HVS. 1995. Maternal aggression in red swamp crayfish (Procambarus clarkii, girard): the relation between reproductive status and outcome of aggressive encounters with male and female conspecifics. Behaviour 132:108121.

Figler MH, Cheverton HM, Blank GS. 1999. Shelter competition in juvenile red swamp crayfish (Procambarus clarkii): the influences of sex differences, relative size, and prior residence. Aquaculture 178: 63-75.

Florey E, Rathmayer M. 1978. The effects of octopamine and other amines on the heart and on neuromuscular transmission in decapod crustaceans: further evidence for a role as neurohormone. Comp Biochem Physiol C 61C:229-237.

Gill MD, Skorupski P. 1996. Modulation of spontaneous and reflex activity of crayfish leg motor neurons by octopamine and serotonin. J Neurophysiol 76:3535-3549.

Glantz RM. 1974. Defense reflex and motion detector responsiveness to approaching targets: the motion detector trigger to the defense reflex pathway. J Comp Physiol 95:297-314.

Glanzman DL, Krasne FB. 1983. Serotonin and octopamine have opposite modulatory effects on the crayfish's lateral giant escape reaction. J Neurosci 3:2263-2269.

Glusman S, Kravitz EA. 1982. The action of serotonin on excitatory nerve terminals in lobster nerve-muscle preparations. J Physiol 325:223-241.

Goessmann C, Hemelrijk C, Huber R. 2001. The formation and maintenance of crayfish hierarchies: behavioral and self-sustaining properties. Behav Ecol Sociobiol 48:418-428.

Harris-Warrick RM, Kravitz EA. 1984. Cellular mechanisms for modulation of posture by octopamine and serotonin in the lobster. J Neurosci 4:1976-1993.

Harris-Warrick RM, Kravitz EA 1985. Amine modulation of extension command element-evoked motor activity in lobster abdomen. J Comp Physiol A 156:875-884.

Herberholz J, Issa FA, Edwards DH. 2001. Patterns of neural circuit activation and behavior during dominance hierarchy formation in freely behaving crayfish. J Neurosci 21:2759-2767.

Huber R, Delago A. 1998. Serotonin alters decisions to withdraw in fighting crayfish, Astacus astacus: the motivational concept revisited. J Comp Physiol A 182:573-583.

Huber R, Kravitz EA. 1995. A quantitative analysis of agonistic behavior in juvenile amercian lobsters (Homarus americanus L.). Brain Behav Evol 46:72-83.

Huber R, Smith K, Delago A, Isaksson K, Kravitz EA. 1997. Serotonin and aggressive motivation in crustaceans: altering the decision to retreat. Proc Natl Acad Sci USA 94:5939-5942.

Huber R, Panksepp JB, Yue Z, Delago A, Moore P. 2001. Dynamic interactions of behavior and amine neurochemistry in acquisition and maintenance of social rank in crayfish. Brain Behav Evol 57: 271-282.

Huxley TH. 1880. The crayfish: an introduction to zoology. New York: D. Appleton \& Co. 
Issa FA, Adamson DJ, Edwards DH. 1999. Dominance hierarchy formation in juvenile crayfish, Procambarus clarkii. J Exp Biol 202:3497-3506.

Jones KA, Page CH. 1986. Postural interneurons in the abdominal nervous system of lobster. III. Pathways mediating intersegmental spread of excitation. J Comp Physiol A 158:281-290.

Katz PS, Harris-Warrick RM. 1990. Neuromodulation of the crab pyloric central pattern generator by serotonergic/cholinergic proprioceptive afferents. J Neurosci 10:1495-1512.

Kelly TM, Chapple WD. 1990. Kinematic analysis of the defense response in crayfish. J Neurophysiol 64:64-76.

Kennedy D, Evoy WH, Hanawalt JT. 1966. Release of coordinated behavior in crayfish by single central neurons. Science 154:917919.

Kovac M. 1974. Abdominal movements during backward walking in crayfish I. properties of the motor program. J Comp Physiol 95:6178.

Krasne FB, Shamsian A, Kulkarni R. 1997. Altered excitability of the crayfish lateral giant escape reflex during agonistic encounters. J Neurosci 17:709-716.

Kravitz EA. 1988. Hormonal control of behavior: Amines and the biasing of behavioral output in lobsters. Science 241:1775-1781.

Kravitz EA. 2000. Serotonin and aggression: insights gained from a lobster model system and speculations on the role of amine neurons in a complex behavior. J Comp Physiol A 186:221-238.

Kravitz EA, Basu AC, Haass FA, Kravitz.. 2001. Crustacean hyperglucemic hormone $(\mathrm{CHH})$ - containing cells in second thoracic roots of the lobster: Intrinsic properties and pharmacological characterization. Soc Neurosci Abstr 27:957.4.

Kuwada JY, Wine JJ. 1979. Crayfish escape behaviour: commands for fast movement inhibit postural tone and reflexes, and prevent habituation of slow reflexes. J Exp Biol 79:205-224.

Kuwada JY, Hagiwara G, Wine JJ. 1980. Postsynaptic inhibition of crayfish tonic flexor motor neurones by escape commands. J Exp Biol 85:343-347.

Leibrock CS, Marchand AR, Barnes WJ, Clarac F. 1996. Synaptic connections of the cuticular stress detectors in crayfish: mono- and polysynaptic reflexes and the entrainment of fictive locomotion in an in vitro preparation. J Comp Physiol [A] 178:711-725.

Livingstone MS, Harris-Warrick RM, Kravitz EA. 1980. Serotonin and octopamine produce opposite postures in lobsters. Science 208: $76-79$.

Lowe ME. 1956. Dominance-subordinance relationships in the crayfish Cambarellus shufeldtii. Tulane Stud Zool 4:139-170.

Ma PM, Beltz BS, Kravitz EA. 1992. Serotonin-containing neurons in lobsters: their role as gain- setters in postural control mechanisms. J Neurophysiol 68:36-54.

Mello JJ, Cromarty SI, Kass-Simon G. 1999. Increased aggressiveness in gravid American lobsters, Homarus americanus. Aggress Behav 25:451-472.

Miall RC, Larimer JL. 1982a. Central organization of crustacean abdominal posture motoneurons: connectivity and command fiber inputs. J Exp Zool 224:45-56.

Miall RC, Larimer JL. 1982b. Interneurons involved in abdominal posture in crayfish: Structure, function and command fiber respones. J Comp Physiol 148:159-173.

Moore D, Larimer JL. 1988. Interactions between the tonic and cyclic postural motor programs in the crayfish abdomen. J Comp Physiol A 163:187-199.

Moore D, Larimer JL. 1993. Cyclic postural behavior in the crayfish, Procambarus clarkii: properties of the pattern-initiating network. J Exp Zool 267:404-415.
Musolf BE, Edwards DH.. 2000. Crayfish hindgut neurons can take up serotonin from different sources in the terminal ganglion. Soc Neurosci Abstr 26:1724.

Pavey CR, Fielder DR. 1996. The influence of size differential on agonistic behaviour in the freshwater crayfish, Cherax cuspidatus (Decapoda: Parastacidae). J Zool (Lond) 238:445-457.

Pearlstein E, Clarac F, Cattaert D. 1998. Neuromodulation of reciprocal glutamatergic inhibition between antagonistic motoneurons by 5-hydroxytryptamine (5-HT) in crayfish walking system. Neurosci Lett 241:37-40.

Peeke HV, Blank GS, Figler MH, Chang ES. 2000. Effects of exogenous serotonin on a motor behavior and shelter competition in juvenile lobsters (Homarus americanus). J Comp Physiol A 186: $575-582$.

Qian SM, Delaney KR. 1997. Neuromodulation of activity-dependent synaptic enhancement at crayfish neuromuscular junction. Brain Res 771:259-270.

Ranta E, Linström K. 1992. Power to hold sheltering burrows by juveniles of the signal crayfish, Pasifastacus leniusculus. Ethology 92:217-226.

Real D, Czternasty G. 1990. Mapping of serotonin-like immunoreactivity in the ventral nerve cord of crayfish. Brain Res 521:203-212.

Rossi-Durand C. 1993. Peripheral proprioceptive modulation in crayfish walking leg by serotonin. Brain Res 632:1-15.

Simon TW, Edwards DH. 1990. Light-evoked walking in crayfish behavioral and neuronal responses triggered by the caudal photoreceptor. J Comp Physiol 166:745-755.

Song C-K, Herberholz J, Drummond J, Edwards DH. 2000. Social experience changes the behavioral response to unexpected touch in crayfish. Soc Neurosci Abstr 26:174.

Sosa MA, Baro DJ. 2001. Distribution of serotonin receptor immunoreactivity in the ventral nerve cord of the freshowater prawn. Soc Neurosci Abstr 27:2131.

Teshiba TM, Shamasian A, Yashar B, Yeh SR, Edwards DH, Krasne FB. 2001. Dual and opposing modulatory effects of serotonin on crayfish lateral giant escape command neurons. J Neurosci 21 4523-4529.

Tierney AJ, Mangiamele LA. 2001. Effects of serotonin and serotonin analogs on posture and agonistic behavior in crayfish. J Comp Physiol A 187:757-767. Online: http://link.springer-ny.com/search. htm.

Tierney AJ, Godleski MS, Rattananont P. 1999. Serotonin-like immunoreactivity in the stomatogastric nervous systems of crayfishes from four genera. Cell Tissue Res. 295:537-551.

Vu ET, Krasne FB. 1993. Crayfish tonic inhibition: prolonged modulation of behavioral excitability by classical GABAergic inhibition. J Neurosci 13:4394-4402.

Vu ET, Lee SC, Krasne FB. 1993. The mechanism of tonic inhibition of crayfish escape behavior: distal inhibition and its functional significance. J Neurosci 13:4379-4393.

Wine JJ, Krasne FB. 1982. The cellular organization of crayfish escape behavior. In: Sandeman DC, Atwood HL, editors. The biology of crustacea. New York: Academic Press. p 241-292.

Yeh SR, Fricke RA, Edwards DH. 1996. The effect of social experience on serotonergic modulation of the escape circuit of crayfish. Science 271:366-369.

Yeh SR, Musolf BE, Edwards DH. 1997. Neuronal adaptations to changes in the social dominance status of crayfish. J Neurosci 17:697-708. 